Research Paper

\title{
Can preoperative and postoperative CA19-9 levels predict survival and early recurrence in patients with resectable hilar cholangiocarcinoma?
}

\author{
Jun-Ke Wang ${ }^{1, *}$, Hai-Jie Hu ${ }^{1, *}$, Anuj Shrestha ${ }^{1,2}$, Wen-Jie Ma ${ }^{1}$, Qin Yang ${ }^{1}$, Fei Liu ${ }^{1}$, \\ Nan-Sheng Cheng ${ }^{1}$ and Fu-Yu Li ${ }^{1}$ \\ ${ }^{1}$ Department of Biliary Surgery, West China Hospital of Sichuan University, Chengdu, Sichuan Province, China \\ ${ }^{2}$ Department of General Surgery, Gandaki Medical College, Pokhara, Nepal \\ *These authors contributed equally to this work \\ Correspondence to: Fu-Yu Li, email: Ify_74@hotmail.com
}

Keywords: hilar cholangiocarcinoma, CA19-9, prognosis, early recurrence

Received: October 07, $2016 \quad$ Accepted: April 11, $2017 \quad$ Published: April 21, 2017

Copyright: Wang et al. This is an open-access article distributed under the terms of the Creative Commons Attribution License 3.0 (CC BY

3.0), which permits unrestricted use, distribution, and reproduction in any medium, provided the original author and source are credited.

\section{ABSTRACT}

Background: To investigate the predictive values of preoperative and postoperative serum CA19-9 levels on survival and other prognostic factors including early recurrence in patients with resectable hilar cholangiocarcinoma.

Results: In univariate analysis, increased preoperative and postoperative CA19-9 levels in the light of different cut-off points $(37,100,150,200,400,1000 \mathrm{U} / \mathrm{ml})$ were significantly associated with poor survival outcomes, of which the cut-off point of $150 \mathrm{U} / \mathrm{ml}$ showed the strongest predictive value (both $P<0.001$ ). Preoperative to postoperative increase in CA19-9 level was also correlated with poor survival outcome $(P<0.001)$. In multivariate analysis, preoperative CA19-9 level $>150 \mathrm{U} / \mathrm{ml}$ was significantly associated with lymph node metastasis (OR $=3.471,95 \%$ CI 1.216-9.905; $P=0.020)$ and early recurrence $(O R=8.280,95 \%$ CI $2.391-28.674 ; P=0.001)$. Meanwhile, postoperative CA19-9 level $>150 \mathrm{U} / \mathrm{ml}$ was also correlated with early recurrence $(O R=4.006,95 \%$ CI 1.107-14.459; $P=0.034)$.

Materials and Methods: Ninety-eight patients who had undergone curative surgery for hilar cholangiocarcinoma between 1995 and 2014 in our institution were selected for the study. The correlations of preoperative and postoperative serum CA19-9 levels on the basis of different cut-off points with survival and various tumor factors were retrospectively analyzed with univariate and multivariate methods.

Conclusions: In patients with resectable hilar cholangiocarcinoma, serum CA19-9 predict survival and early recurrence. Patients with increased preoperative and postoperative CA19-9 levels have poor survival outcomes and higher tendency of early recurrence.

\section{INTRODUCTION}

Hilar cholangiocarcinoma (HCCA) is featured by advanced tumor biology, low surgical resectability, high recurrence and poor survival outcome [1-4]. On account of the absence of particular related symptoms in early stage, most patients with HCCA manifest locally advanced disease and unresectable when diagnosed [5]. With the progress of surgical techniques, more and more patients are eligible for curative surgery [6], which furnishes the only possibility of long term survival $[7,8]$. However, the prognosis of HCCA is still deplorable [9-11].

Serum carbohydrate antigen 19-9 (CA19-9) has been extensively applied in conventional clinical practices for diagnosis, treatment options, prognosis and therapeutic response detection in HCCA [12-14]. Nevertheless, the prognostic effect of CA19-9 levels on survival remains disputable: several investigators have reported increased preoperative CA19-9 levels predict poor survival outcome [15-17], while others noted that preoperative 
CA19-9 has no specific association with survival outcome $[18,19]$. In addition, the majority of patients with HCCA have hyperbilirubinemia, and hyperbilirubinemia leads to a significant increase in preoperative CA19-9 level $[15,16,20]$. However, most previous studies have ignored the role of hyperbilirubinemia on CA19-9 level, and if patients with hyperbilirubinemia were taken into consideration, the results may be biased. Furthermore, serum CA19-9 concentration is determined by the Lewis phenotype on red blood cells $[16,21]$. However, about $5 \%-14 \%$ of the population are Lewis ${ }^{\mathrm{a}-\mathrm{b}-}$ and these individuals cannot produce CA19-9 (CA19-9 nonsecretory) when they suffer from malignant diseases [4]; even after curative resection, these patients tend to have poor prognosis. Previous studies have also overlooked this significant factor and have not rule out these patients when examining the prognostic effect of CA19-9 levels on HCCA. In view of the above factors, prognostic effect of preoperative CA19-9 levels on survival in previous studies should be modified. Moreover, the prognostic role of postoperative CA19-9 levels and the preoperative to postoperative CA19-9 changes on survival and early recurrence have merely not been investigated in former studies.

The aim of the present study was therefore to retrospectively analyze the prognostic values of preoperative and postoperative CA19-9 levels on survival outcome after curative resection of HCCA in those without CA19-9 nonsecretory and hyperbilirubinemia. Preoperative to postoperative CA19-9 changes on survival were simultaneously analyzed. Furthermore, we also assessed the relationships of preoperative and postoperative CA19-9 levels with various clinicopathological factors including early recurrence (recurrence $<12$ months after curative surgery) by using the univariate and multivariate methods.

\section{RESULTS}

\section{Patient characters}

Table 1 outlined the fundamental clinicopathological features of the patients. The median preoperative total bilirubin level after biliary drainage was 23.9 umol/1, and the corresponding median preoperative CA19-9 level was $129.6 \mathrm{U} / \mathrm{ml}$. The median postoperative CA19-9 level was $36.1 \mathrm{U} / \mathrm{ml}$. All patients were operated on with curative surgery with postoperative R0 (87 cases) and R1 (11 cases) margin status. The postoperative complications after curative surgery were detected in 22 patients, which includes bile leakage ( 8 cases), lung infection (4 cases), hemorrhage (3 cases), peritoneal cavity infection (3 cases), hepatic failure ( 2 cases), sepsis ( 1 case), and acute cardiac failure (1 case). No postoperative deaths were detected among the 98 patients, and all of the patients were well followed-up. We examined the early recurrence in 28 of the 98 patients at the first year after surgery, of which local recurrence $(n=13)$ and liver metastasis $(n=8)$ were most commonly to see. The median overall survival time of the 98 patients after curative surgery was 36.8 months with a 1 -, 3-, 5-year survival rate of $83 \%, 51 \%$, and $30 \%$ respectively.

\section{Preoperative and postoperative CA19-9 levels on survival}

Differences in survival outcome were statistically significant between groups divided in the light of the six preoperative CA19-9 cut-off points $(37,100,150,200$, $400,1000 \mathrm{U} / \mathrm{ml}$, the corresponding $P$ values of which were $0.035,0.028,<0.001,0.026,0.010$ and 0.010 respectively; Table 2). Excluding the cut-off points of 400 and $1000 \mathrm{U} / \mathrm{ml}$ with fewer number of patient cases, the preoperative CA19-9 cut-off point of $150 \mathrm{U} / \mathrm{ml}$ showed the strongest predictive value (Figure $1, P<0.001$ ). And then, statistical differences in postoperative CA19-9 levels divided on the basis of the six cut-off points were also confirmed (cut-off points: 37, 100, 150, 200, 400, 1000 $\mathrm{U} / \mathrm{ml}$, the corresponding $P$ values were $0.004,0.013$, $<0.001,0.006,<0.001$ and $<0.001$ respectively; Table 2 ). Similarly, the postoperative CA19-9 cut-off point of $150 \mathrm{U} / \mathrm{ml}$ was also regarded as the strongest predictive value associated with survival (Figure 2, $P<0.001$ ).

\section{Preoperative to postoperative CA19-9 alterations on survival}

In order to examine the preoperative to postoperative CA19-9 changes on survival, we excluded those with preoperative CA19-9 levels within the base line point $(\leq 37 \mathrm{U} / \mathrm{ml}, n=10)$, and then we divided patients into 3 groups based on the transformation of CA19-9 levels: patients with postoperative CA19-9 increased $(n=9)$, patients with postoperative CA19-9 decreased $\leq 50 \%$ $(n=36)$, and patients with postoperative CA19-9 decreased $>50 \%(n=43)$. Patients with increased postoperative CA19-9 levels had a poor median survival time of 12.6 months, while decreased postoperative CA19-9 levels $\leq 50 \%$ conferred to a median survival time of 28.4 months. Finally, in the last group with CA19-9 decreased $>50 \%$, a relatively better median survival time of 38.1 months was expected (Figure $3, P<0.001$ ).

\section{Preoperative and postoperative CA19-9 levels with various tumor factors}

Because the preoperative and postoperative CA19-9 cut-off points of $150 \mathrm{U} / \mathrm{ml}$ indicated the strongest predictive significance associated with survival. Then we further analyzed the relationships of preoperative and postoperative CA19-9 levels with other prognostic factors using the cut-off point of $150 \mathrm{U} / \mathrm{ml}$ (Table 3). In 
Table 1: Clinicopathologic characters of 98 hilar cholangiocarcinoma patients treated by curative resection

\begin{tabular}{|c|c|}
\hline Variables & $n=98$ \\
\hline Age, years* & $60[36-79]$ \\
\hline Sex (male/female) & $51 / 47$ \\
\hline Preoperative TB level, umol//*, & $23.9[7.1-34.2]$ \\
\hline Preoperative ALT level, U/L* & $109[13-720]$ \\
\hline Preoperative AST level, U/L* & $94[14-387]$ \\
\hline Preoperative Albumin level, g/L* & $38.1[31-50.1]$ \\
\hline Preoperative CA19-9 level, U/ml* & $129.6[11.7->1000]$ \\
\hline Preoperative CA125 level, U/ml ${ }^{*}$ & $20.1[2.5-120.9]$ \\
\hline Preoperative CEA level, ng/ml ${ }^{*}$ & $2.7[0.2-38.2]$ \\
\hline Total hospital stay, days* & $19[10-113]$ \\
\hline Preoperative biliary drainage (no/yes) & $83 / 15$ \\
\hline Portal vein embolization (no/yes) & $84 / 14$ \\
\hline \multicolumn{2}{|l|}{ Tumor extent (Bismuth-Corlette classification) } \\
\hline Type I and II & $61(62.2)$ \\
\hline Type III and IV & $37(37.8)$ \\
\hline \multicolumn{2}{|l|}{ Surgical procedures } \\
\hline Bile duct resection & $11(11.2)$ \\
\hline left hemihepatectomy & $46(46.9)$ \\
\hline right hemihepatectomy & $30(30.6)$ \\
\hline left trisegmentectomy & $6(6.1)$ \\
\hline right trisegmentectomy & $3(3.1)$ \\
\hline mesohepatetctomy & $2(2.0)$ \\
\hline caudate lobectomy (no/yes) & $24 / 74$ \\
\hline Portal vein resection and reconstruction (no/yes) & $13 / 85$ \\
\hline \multicolumn{2}{|l|}{ AJCC 7th T Stage } \\
\hline $\mathrm{T} 1$ and $\mathrm{T} 2$ & $70(71.4)$ \\
\hline $\mathrm{T} 3$ and $\mathrm{T} 4$ & $28(28.6)$ \\
\hline Tumor size* & $2.9[1-6]$ \\
\hline Postoperative CA19-9 level* & $36.1[7.2->1000]$ \\
\hline Tumor resection margin (R0/R1) & $87 / 11$ \\
\hline Lymph node metastasis (no/yes) & $58 / 40$ \\
\hline
\end{tabular}


Tumor differentiation (well/moderate/poor)

Vascular invasion (no/yes)

Complications (no/yes)

Early recurrence (no/yes) ${ }^{\&}$

Survival time, months*
$27 / 46 / 25$

$82 / 16$

$76 / 22$

$70 / 28$

$36.8[5.6-84.8]$

*indicated as median and range; †indicated as the bilirubin level just before the surgery; \&indicated as recurrence $<12$ months after curative surgery; TB: total bilirubin; ALT: alanine aminotransferase. AST: aspartate transaminase; CA199: carbohydrate antigen 19-9; CA125: carbohydrate antigen 125; CEA: carcino embryonie antigen; AJCC: American Joint Committee On Cancer.

the univariate analysis, preoperative aspartate transaminase (AST) level $>40 \mathrm{U} / \mathrm{L}(P=0.017)$, lymph node metastasis $(P=0.001)$, vascular invasion $(P=0.017)$, and early recurrence $(P<0.001)$ were associated with preoperative CA19-9 levels. In contrast, postoperative CA19-9 levels were obviously higher in those female patients $(P=0.002)$ with preoperative biliary drainage $(P=0.021)$, lymph node metastasis $(P=0.013)$, and early recurrence $(P=0.003)$.

Then, a multivariate logistic regression model was conducted to analyze the significant factors (Table 4).
The analysis identified patients with preoperative CA19-9 level $>150 \mathrm{U} / \mathrm{ml}$ were significantly associated with lymph node metastasis (OR [odds ratio] $=3.471$, 95\% CI 1.216-9.905; $P=0.020)$ and early recurrence $(\mathrm{OR}=8.280,95 \%$ CI 2.391-28.674; $P=0.001)$. Patients with preoperative CA19-9 $>150 \mathrm{U} / \mathrm{ml}$ are easy to suffer vascular invasion $(\mathrm{OR}=3.643,95 \%$ CI $0.955-13.897$; $P=0.058)$, however, it did not reach statistical significance. Meanwhile, postoperative CA19-9 level $>150 \mathrm{U} / \mathrm{ml}$ was also correlated with early recurrence

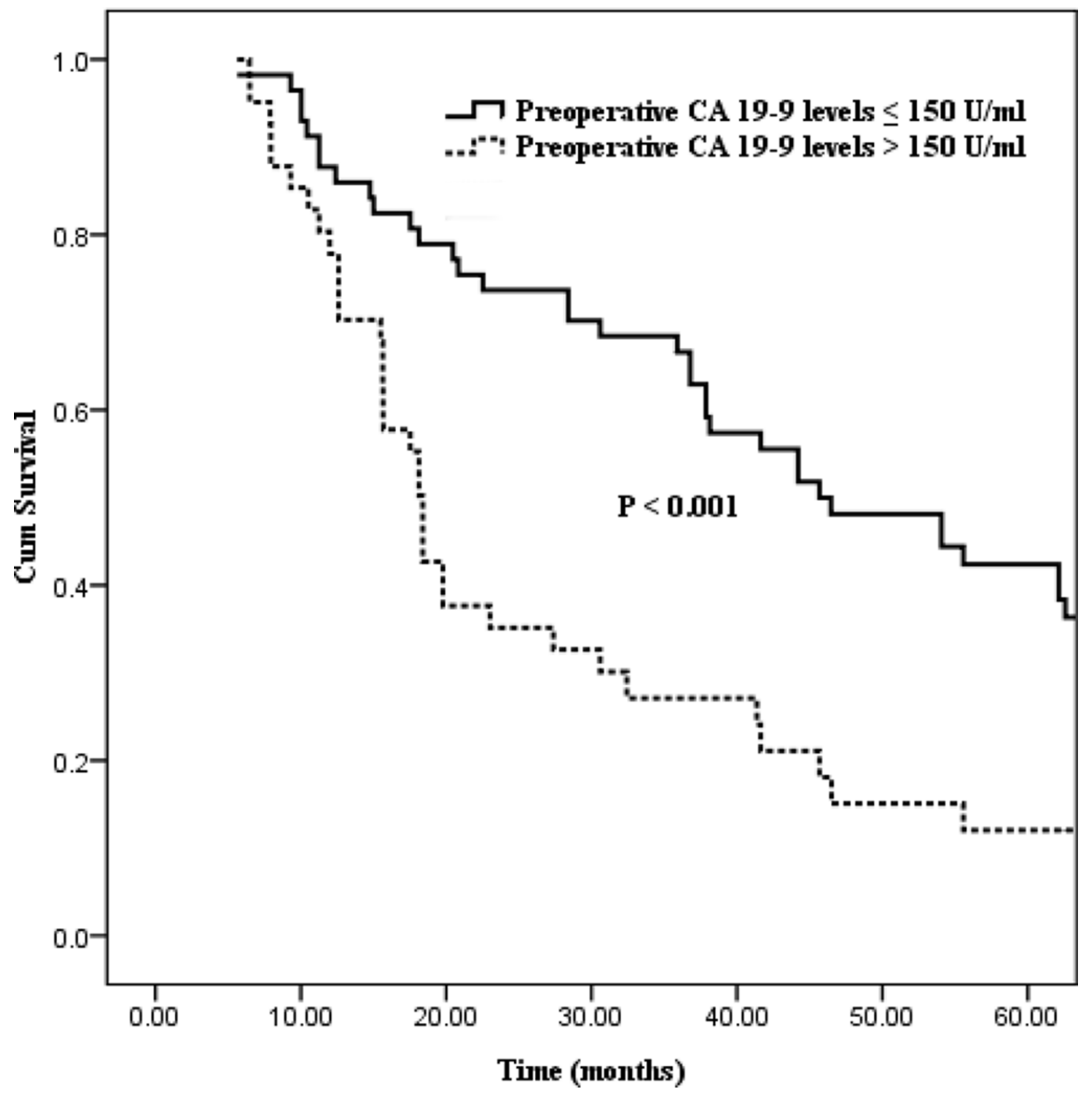

Figure 1: Kaplan-Meier curves comparing survival status stratified by preoperative CA19-9 levels $(\leq 150 \mathrm{U} / \mathrm{ml}$ vs. $>150 \mathrm{U} / \mathrm{ml} ; P<0.001)$. 
Table 2: Differences of overall survival in two groups divided on the basis of six CA19-9 cut-off points for 98 patients treated by curative resection for hilar cholangiocarcinoma

\begin{tabular}{|c|c|c|c|c|c|c|}
\hline \multirow[b]{2}{*}{$\begin{array}{l}\text { CA19-9 cut-off } \\
\text { point* }\end{array}$} & \multicolumn{3}{|c|}{ Preoperative CA19-9 levels } & \multicolumn{3}{|c|}{ Postoperative CA19-9 levels } \\
\hline & $\begin{array}{l}\text { Patients } \\
\text { number }\end{array}$ & $\begin{array}{l}\text { Median survival } \\
\text { (Months) }\end{array}$ & $P$ value & $\begin{array}{l}\text { Patients } \\
\text { number }\end{array}$ & $\begin{array}{l}\text { Median survival } \\
\text { (Months) }\end{array}$ & $P$ value \\
\hline$\leq 37$ & 10 & 63.6 & 0.035 & 55 & 44.2 & 0.004 \\
\hline$>37$ & 88 & 30.6 & & 43 & 18.4 & \\
\hline$\leq 100$ & 31 & 54.1 & 0.028 & 71 & 38.1 & 0.013 \\
\hline$>100$ & 67 & 28.4 & & 27 & 17.9 & \\
\hline$\leq 150$ & 57 & 45.7 & $<0.001$ & 82 & 38.1 & $<0.001$ \\
\hline$>150$ & 41 & 18.4 & & 16 & 12.6 & \\
\hline$\leq 200$ & 82 & 37.9 & 0.026 & 85 & 37.6 & 0.006 \\
\hline$>200$ & 16 & 15.5 & & 13 & 15.2 & \\
\hline$\leq 400$ & 89 & 36.8 & 0.010 & 92 & 37.8 & $<0.001$ \\
\hline$>400$ & 9 & 10.5 & & 6 & 7.9 & \\
\hline$\leq 1000$ & 94 & 36.7 & 0.010 & 97 & 36.8 & $<0.001$ \\
\hline$>1000$ & 4 & 7.9 & & 1 & 6.5 & \\
\hline
\end{tabular}

*the unit is U/ml; CA19-9: carbohydrate antigen 19-9.



Figure 2: Kaplan-Meier curves comparing survival status stratified by postoperative CA19-9 levels $(\leq 150 \mathrm{U} / \mathrm{ml} \mathrm{vs}$. $>150 \mathrm{U} / \mathrm{ml} ; P<0.001$ ). 
$(\mathrm{OR}=4.006,95 \%$ CI 1.107-14.459; $P=0.034)$. Similarly, patients have a higher tendency of lymph node metastasis $(\mathrm{OR}=3.427,95 \%$ CI $0.913-12.864 ; P=0.068)$ when postoperative CA19-9 level $>150 \mathrm{U} / \mathrm{ml}$, but it did not reach statistical significance.

\section{DISCUSSION}

Currently, there are almost no studies in the literature that have comprehensively analyzed the prognostic influences of different cut-off points of preoperative and postoperative serum CA19-9 levels on survival of $\mathrm{HCCH}$. Meanwhile, the ideal cut-off point in predicting survival and other prognostic factors, including early recurrence, has remained controversial. Furthermore, the predictive value of preoperative to postoperative CA19-9 alterations on survival has also not been well defined. Thus, it is now, our time to systematically elucidate the predictive values of preoperative and postoperative CA19-9 levels on survival and other prognostic factors, and which cut-off value of CA19-9 levels showed the strongest predictive value in HCCA.

To achieve the above goal, our current study divided the preoperative and postoperative CA19-9 levels into different groups based on the cut-off points of 37, 100,
$150,200,400,1000 \mathrm{U} / \mathrm{ml}$, which were selected in the light of many previous studies and the distribution of CA19-9 levels in our current study. Our results revealed that increased preoperative CA19-9 levels were associated with poor survival outcomes. Of the six cut-off points, $150 \mathrm{U} / \mathrm{ml}$ revealed the strongest predictive value, which was consistent with the previous studies [16]. Different from previous studies, our study was not affected by elevated preoperative bilirubin levels because it was reported hyperbilirubinemia leads to a significant increase in CA19-9 level. Also different from former researches, we excluded those with CA19-9 nonsecretory, if were included in the research, the results would undoubtedly to be affected. Besides, our study also analyzed the relationships of different postoperative CA19-9 levels on survival and various tumor factors after curative resection. Similarly, the six cut-off points of postoperative CA19-9 levels were also identified as prognostic factors for HCCA, and the cut-off point of $150 \mathrm{U} / \mathrm{ml}$ simultaneously showed the strongest predictive value. To our knowledge, postoperative CA19-9 levels on survival had not been analyzed in previous literature. The postoperative CA19-9 levels of the 98 patients in our study were measured between 1 and 3 months after curative surgery. In viewing of this respect, conventional

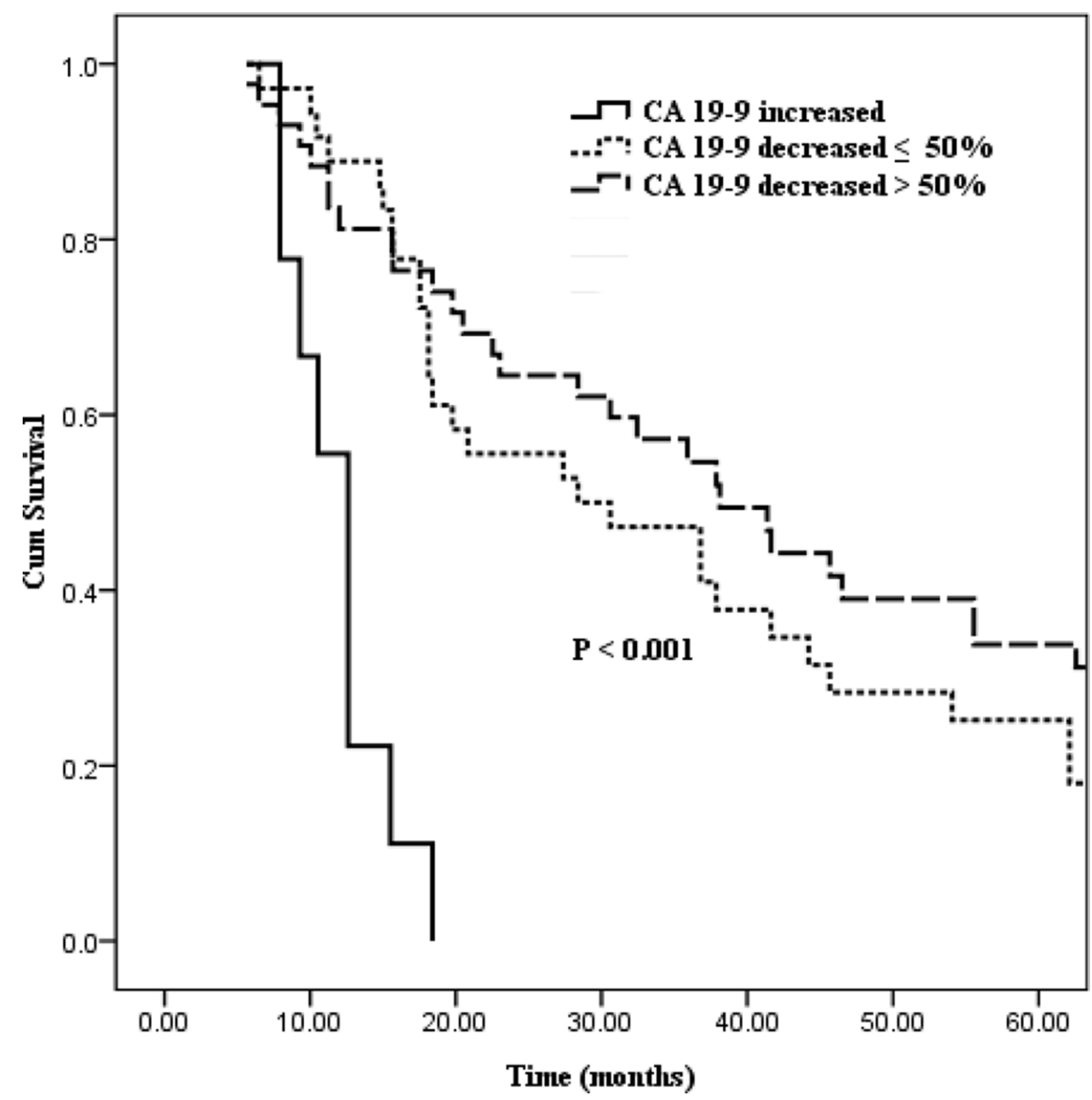

Figure 3: Kaplan-Meier curves comparing survival status stratified by preoperative to postoperative CA19-9 alterations (increased vs. decreased $\leq 50 \%$ vs. decreased $>50 \% ; P<0.001$ ). 
Table 3: Univariate analysis of preoperative and postoperative CA19-9 levels with various tumor factors

\begin{tabular}{|c|c|c|c|c|c|c|}
\hline \multirow[b]{2}{*}{ Variables } & \multicolumn{2}{|c|}{$\begin{array}{c}\text { Preoperative CA19-9 } \\
\text { levels* }\end{array}$} & \multicolumn{4}{|c|}{$\begin{array}{c}\text { Postoperative CA19-9 } \\
\text { levels* }\end{array}$} \\
\hline & $\begin{array}{c}\leq 150 \\
(n=57)\end{array}$ & $\begin{array}{c}>150 \\
(n=41)\end{array}$ & $P$ value & $\begin{array}{c}\leq 150 \\
(n=82)\end{array}$ & $\begin{array}{c}>150 \\
(n=16)\end{array}$ & $P$ value \\
\hline \multicolumn{7}{|l|}{ Gender } \\
\hline Male & $25(43.9)$ & $26(63.4)$ & 0.056 & $45(54.9)$ & $2(12.5)$ & 0.002 \\
\hline Female & $32(56.1)$ & $15(36.6)$ & & $37(45.1)$ & $14(87.5)$ & \\
\hline \multicolumn{7}{|c|}{ Preoperative AST level $>40 \mathrm{U} / \mathrm{L}$} \\
\hline No & $17(29.8)$ & $4(9.8)$ & 0.017 & $20(24.4)$ & $1(6.3)$ & NS \\
\hline Yes & $40(70.2)$ & $37(90.2)$ & & $62(75.6)$ & $15(93.8)$ & \\
\hline \multicolumn{7}{|c|}{ Preoperative biliary drainage } \\
\hline No & $51(89.5)$ & $32(78)$ & NS & $73(89)$ & $10(62.5)$ & 0.021 \\
\hline Yes & $6(10.5)$ & $9(22)$ & & $9(11)$ & $6(37.5)$ & \\
\hline \multicolumn{7}{|c|}{ Lymph node metastasis } \\
\hline No & $42(73.7)$ & $16(39)$ & 0.001 & $53(64.6)$ & $5(31.2)$ & 0.013 \\
\hline Yes & $15(26.3)$ & $25(61)$ & & $29(35.4)$ & $11(68.8)$ & \\
\hline \multicolumn{7}{|c|}{ Vascular invasion } \\
\hline No & $52(91.2)$ & $30(73.2)$ & 0.017 & $70(85.4)$ & $12(75)$ & NS \\
\hline Yes & $5(8.8)$ & $11(26.8)$ & & $12(14.6)$ & $4(25)$ & \\
\hline \multicolumn{7}{|c|}{ Early recurrence $\dagger$} \\
\hline No & $51(89.5)$ & $19(46.3)$ & $<0.001$ & $64(78)$ & $6(37.5)$ & 0.003 \\
\hline Yes & $6(10.5)$ & $22(53.7)$ & & $18(22)$ & $10(62.5)$ & \\
\hline
\end{tabular}

"Present as number (\%); "Early recurrence defined as recurrence $<12$ months after curative surgery;

Factors did not associated with CA19-9 levels included age, total hospital stay, preoperative CEA levels, preoperative CA125 levels, Bismuth-Corlette classification, caudate lobectomy, preoperative ALT levels, preoperative albumin levels, preoperative biliary drainage, portal vein embolization, tumor size, tumor differentiation, AJCC 7th T stage, surgical procedures, postoperative complications et al.

CA19-9: carbohydrate antigen 19-9; CA125: carbohydrate antigen 125; NS: not significant; AST: aspartate transaminase.

Table 4: Multivariate analysis of significant factors among previous univariate analysis with CA19-9 levels

\begin{tabular}{lcccccc}
\hline & \multicolumn{3}{c}{ Preoperative CA19-9 levels } & \multicolumn{2}{c}{ Postoperative CA 19-9 levels } \\
\hline Variables & odds ratio & $\mathbf{9 5 \%}$ CI & $\boldsymbol{P}$ value & odds ratio & 95\% CI & $\boldsymbol{P}$ value \\
\hline Lymph node metastasis & 3.471 & $1.216-9.905$ & 0.020 & 3.427 & $0.913-12.864$ & 0.068 \\
Vascular invasion & 3.643 & $0.955-13.897$ & 0.058 & - & - & - \\
Early recurrence & 8.280 & $2.391-28.674$ & 0.001 & 4.006 & $1.107-14.459$ & 0.034 \\
\hline
\end{tabular}

CA19-9: carbohydrate antigen 19-9.

monitoring of the postoperative CA19-9 level within 1-3 months after surgery is a must and postoperative CA19-9 may be also recommended as a predictive factor to survival.

In addition, our study also assessed preoperative to postoperative CA19-9 alterations on survival. CA19-9 alterations could indirectly predict the disease evolution and increased postoperative CA19-9 is a reflection of tumor recurrence. Our results demonstrated that patients with increased postoperative CA19-9 tend to have poor survival outcome. Thus, attentions should also be paid on the preoperative to postoperative CA19-9 alterations so as to better predict the survival and tumor recurrence after surgery. 
More importantly, our study also focused on the predictive values of preoperative and postoperative CA19-9 levels on various tumor factors before and after surgery. Our results showed that increased preoperative CA19-9 level has a higher tendency of lymph node metastasis, vascular invasion, and early recurrence. Meanwhile, early recurrence was also demonstrated as an independent factor with postoperative CA19-9 cut-off value of $150 \mathrm{U} / \mathrm{ml}$. Many previous studies have reported patients with lymph node metastasis, vascular invasion and early recurrence are doubtlessly to have poor survival and have well been established as prognostic factors for survival after curative surgery of HCCA [22-26]. Thus, based on our results, we believe that CA19-9 levels can indirectly affect survival and increased preoperative and postoperative CA19-9 levels are associated with poor survival. Therefore, the preoperative CA19-9 levels should be taken into consideration when assessing the proper surgical procedures for relevant patients. Meanwhile, the postoperative CA19-9 levels should also be regularly monitored so as to help in early detection of tumor recurrence and lymph node metastasis.

Based on the retrospective nature of our current study with only 98 patients, future prospective analysis with more patient numbers or multi-center cooperation is undoubtedly needed to better clarify the prognostic effect of preoperative and postoperative CA19-9 levels on survival and various tumor factors, so as to better guide the treatment and predict survival.

In conclusion, patients with increased preoperative and postoperative CA19-9 levels have a higher tendency of lymph node metastasis and early recurrence in patients with resectable hilar cholangiocarcinoma. On the one hand, increased CA19-9 levels can directly predict poor survival outcome. On the other hand, CA19-9 levels can impact lymph node metastasis, vascular invasion, early recurrence, and then indirectly affect survival.

\section{MATERIALS AND METHODS}

\section{Patient selection}

From January 1995 to December 2014, a total of 98 patients diagnosed with HCCA who underwent curative surgery (including $\mathrm{R} 0$ and $\mathrm{R} 1$ resection) and with exploitable CA19-9 levels from West China Hospital of Sichuan University were retrospectively included. Patients with $\mathrm{R} 2$ resection and palliative surgery were excluded. Both patients with hyperbilirubinemia (preoperative total bilirubin levels $>34.2$ umol/1 after biliary drainage) and those with CA19-9 nonsecretory (preoperative serum CA19-9 levels $<5 \mathrm{U} / \mathrm{ml}$ ) were also excluded. None of the included patients accepted any anti-cancer treatment prior to surgery. A diagnosis of hilar bile duct adenocarcinoma was acknowledged histologically in all cases.

\section{Data collection}

Serum CA19-9 level was detected using Roche chemiluminescence immunoassay kit. Preoperative serum CA19-9 was detected just before the surgery so as to evade the effect of hyperbilirubinemia on CA19-9 level. Postoperative serum CA19-9 level was measured between 1 and 3 months after surgery. Preoperative biliary drainage was conducted on patients with obstructive jaundice using endoscopic retrograde biliary drainage or percutaneous transhepatic biliary drainage. Patients with preoperative total bilirubin levels $>34.2 \mathrm{umol} / \mathrm{l}$ after biliary drainage were excluded. Both preoperative and postoperative CA19-9 levels were divided as $\leq 37 \mathrm{U} / \mathrm{ml}$ vs. $>37 \mathrm{U} / \mathrm{ml}$, $\leq 100 \mathrm{U} / \mathrm{ml}$ vs. $>100 \mathrm{U} / \mathrm{ml}, \leq 150 \mathrm{U} / \mathrm{ml} \mathrm{vs.}>150 \mathrm{U} / \mathrm{ml}$, $\leq 200 \mathrm{U} / \mathrm{ml}$ vs. $>200 \mathrm{U} / \mathrm{ml}, \leq 400 \mathrm{U} / \mathrm{ml}$ vs. $>400 \mathrm{U} / \mathrm{ml}, \leq 1000 \mathrm{U} / \mathrm{ml}$ vs. $>1000 \mathrm{U} / \mathrm{ml}$. These cut-off values were selected in the light of many previous studies and the distribution of CA19-9 levels in our current study $[15,16,22,27,28]$.

\section{Postoperative follow-up}

Patients were strictly monitored at outpatient department after surgery. Regular laboratory tests such as liver functions, and tumor markers were conducted and abdominal ultrasound was routinely proceed every 2-3 months during the first year, then 3-6 months yearly thereafter. Computed tomography scan of abdomen or magnetic resonance imaging test was further adopted if patients were suspected as tumor recurrence.

\section{Statistical analysis}

Patient characteristics were conveyed using frequency or descriptive analysis. The Kaplan-Meier analysis and log-rank test were adopted to analyze the difference in overall survival between groups divided based on the six cut-off points of preoperative and postoperative CA19-9 levels listed above. Preoperative to postoperative CA19-9 changes on survival were simultaneously analyzed using the same methods. The CA19-9 cut-off point showing the strongest significance was further examined using the univariate and multivariate logistic regression models, and many preoperative and postoperative factors including early recurrence were analyzed so as to identify the independent factors associated with CA19-9 levels. The $P$ value $<0.05$ was deemed as significant. The statistical analysis was outlined using the SPSS version16.0 (SPSS Inc. Chicago, IL, USA).

\section{Abbreviations}

Hilar cholangiocarcinoma (HCCA); Carbohydrate antigen 19-9 (CA19-9). 


\section{Authors' contributions}

Jun-Ke Wang and Hai-Jie Hu contributed equally to this paper. Jun-Ke Wang and Hai-Jie Hu contributed to the analysis and drafted the manuscript. Wen-Jie Ma, Qin Yang and Fei Liu contributed to data acquisition and analyzed the manuscript. Anuj Shrestha, Nan-Sheng Cheng were involved in the revision of the manuscript. $\mathrm{Fu}-\mathrm{Yu} \mathrm{Li}$ contributed to the study design and revision of the manuscript. All authors read and approved the final manuscript.

\section{ACKNOWLEDGMENTS AND FUNDING}

We acknowledged that this study was supported by the National Nature Science of China (30801111, 30972923) and Science \& Technology Support Project of Sichuan Province (No.2014SZ0002-10).

\section{CONFLICTS OF INTEREST}

We declare that we have no conflicts of interest.

\section{REFERENCES}

1. Saxena A, Chua TC, Chu FC, Morris DL. Improved outcomes after aggressive surgical resection of hilar cholangiocarcinoma: a critical analysis of recurrence and survival. Am J Surg. 2011; 202:310-320.

2. Ercolani G, Zanello M, Grazi GL, Cescon M, Ravaioli M, Del Gaudio M, Vetrone G, Cucchetti A, Brandi G, Ramacciato G, Pinna AD. Changes in the surgical approach to hilar cholangiocarcinoma during an 18-year period in a Western single center. J Hepatobiliary Pancreat Sci. 2010; 17:329-337.

3. Burke EC, Jarnagin WR, Hochwald SN, Pisters PW, Fong Y, Blumgart LH. Hilar Cholangiocarcinoma: patterns of spread, the importance of hepatic resection for curative operation, and a presurgical clinical staging system. Ann Surg. 1998; 228:385-394.

4. Hu HJ, Mao H, Tan YQ, Shrestha A, Ma WJ, Yang Q, Wang JK, Cheng NS, Li FY. Clinical value of preoperative serum CA 19-9 and CA 125 levels in predicting the resectability of hilar cholangiocarcinoma. Springerplus. 2016; 5:551.

5. Golfieri R, Giampalma E, Renzulli M, Galuppi A, Vicenzi L, Galaverni MC, Cappelli A. Unresectable hilar cholangiocarcinoma: multimodality approach with percutaneous treatment associated with radiotherapy and chemotherapy. In Vivo. 2006; 20:757-760.

6. Yang WL, Zhang XC, Zhang DW, Tong BF. Diagnosis and surgical treatment of hepatic hilar cholangiocarcinoma. Hepatobiliary Pancreat Dis Int. 2007; 6:631-635.

7. Jarnagin WR, Fong Y, DeMatteo RP, Gonen M, Burke EC, Bodniewicz BJ, Youssef BM, Klimstra D, Blumgart LH.
Staging, resectability, and outcome in 225 patients with hilar cholangiocarcinoma. Ann Surg. 2001; 234:507-517.

8. Xiong J, Nunes QM, Huang W, Wei A, Ke N, Mai G, Liu X, $\mathrm{Hu}$ W. Major hepatectomy in Bismuth types I and II hilar cholangiocarcinoma. J Surg Res. 2015; 194:194-201.

9. Shingu Y, Ebata T, Nishio H, Igami T, Shimoyama Y, Nagino M. Clinical value of additional resection of a marginpositive proximal bile duct in hilar cholangiocarcinoma. Surgery. 2010; 147:49, 56.

10. Li H, Qin Y, Cui Y, Chen H, Hao X, Li Q. Analysis of the surgical outcome and prognostic factors for hilar cholangiocarcinoma: a Chinese experience. Dig Surg. 2011; 28:226-231.

11. Ruys AT, van Haelst S, Busch OR, Rauws EA, Gouma DJ, van Gulik TM. Long-term survival in hilar cholangiocarcinoma also possible in unresectable patients. World J Surg. 2012; 36:2179-2186.

12. Soares KC, Kamel I, Cosgrove DP, Herman JM, Pawlik TM. Hilar cholangiocarcinoma: diagnosis, treatment options, and management. Hepatobiliary Surg Nutr. 2014; 3:18-34.

13. Rerknimitr R, Angsuwatcharakon P, Ratanachu-ek T, Khor CJ, Ponnudurai R, Moon JH, Seo DW, PantongragBrown L, Sangchan A, Pisespongsa P, Akaraviputh T, Reddy ND, Maydeo A, et al. Asia-Pacific consensus recommendations for endoscopic and interventional management of hilar cholangiocarcinoma. J Gastroenterol Hepatol. 2013; 28:593-607.

14. LaFemina J, Jarnagin WR. Surgical management of proximal bile duct cancers. Langenbecks Arch Surg. 2012; 397:869-879.

15. Juntermanns B, Radunz S, Heuer M, Hertel S, Reis H, Neuhaus JP, Vernadakis S, Trarbach T, Paul A, Kaiser GM. Tumor markers as a diagnostic key for hilar cholangiocarcinoma. Eur J Med Res. 2010; 15:357-361.

16. Cai WK, Lin JJ, He GH, Wang H, Lu JH, Yang GS. Preoperative serum CA19-9 levels is an independent prognostic factor in patients with resected hilar cholangiocarcinoma. Int J Clin Exp Pathol. 2014; 7:7890-7898.

17. Chaiteerakij R, Harmsen WS, Marrero CR, Aboelsoud MM, Ndzengue A, Kaiya J, Therneau TM, Sanchez W, Gores GJ, Roberts LR. A new clinically based staging system for perihilar cholangiocarcinoma. Am J Gastroenterol. 2014; 109:1881-1890.

18. Ramacciato G, Nigri G, Bellagamba R, Petrucciani N, Ravaioli M, Cescon M, Del Gaudio M, Ercolani G, Di Benedetto F, Cautero N, Quintini C, Cucchetti A, Lauro A, et al. Univariate and multivariate analysis of prognostic factors in the surgical treatment of hilar cholangiocarcinoma. Am Surg. 2010; 76:1260-1268.

19. Sano T, Shimada K, Sakamoto Y, Ojima H, Esaki M, Kosuge T. Prognosis of perihilar cholangiocarcinoma: hilar bile duct cancer versus intrahepatic cholangiocarcinoma involving the hepatic hilus. Ann Surg Oncol. 2008; 15: 590-599.

20. Harder J, Kummer O, Olschewski M, Otto F, Blum HE, Opitz O. Prognostic relevance of carbohydrate antigen 19-9 
levels in patients with advanced biliary tract cancer. Cancer Epidemiol Biomarkers Prev. 2007; 16:2097-2100.

21. Liu L, Xu H, Wang W, Wu C, Chen Y, Yang J, Cen P, Xu J, Liu C, Long J, Guha S, Fu D, Ni Q, et al. A preoperative serum signature of CEA+/CA125+/CA19-9 >/= $1000 \mathrm{U} / \mathrm{mL}$ indicates poor outcome to pancreatectomy for pancreatic cancer. Int J Cancer. 2015; 136:2216-2227.

22. Seyama Y, Kubota K, Sano K, Noie T, Takayama T, Kosuge T, Makuuchi M. Long-term outcome of extended hemihepatectomy for hilar bile duct cancer with no mortality and high survival rate. Ann Surg. 2003; 238:73-83.

23. Klempnauer J, Ridder GJ, Werner M, Weimann A, Pichlmayr R. What constitutes long-term survival after surgery for hilar cholangiocarcinoma? Cancer. 1997; 79:26-34.

24. Klempnauer J, Ridder GJ, von Wasielewski R, Werner M, Weimann A, Pichlmayr R. Resectional surgery of hilar cholangiocarcinoma: a multivariate analysis of prognostic factors. J Clin Oncol. 1997; 15:947-954.
25. DeOliveira ML, Cunningham SC, Cameron JL, Kamangar F, Winter JM, Lillemoe KD, Choti MA, Yeo CJ, Schulick RD. Cholangiocarcinoma: thirty-one-year experience with 564 patients at a single institution. Ann Surg. 2007; 245:755-762.

26. Hu HJ, Mao H, Shrestha A, Tan YQ, Ma WJ, Yang Q, Wang JK, Cheng NS, Li FY. Prognostic factors and longterm outcomes of hilar cholangiocarcinoma: A singleinstitution experience in China. World J Gastroenterol. 2016; 22:2601-2610.

27. Wang Y, Yang H, Shen C, Luo J. Surgical procedure and long-term survival of hilar cholangiocarcinoma. Int J Clin Exp Med. 2015; 8:1122-1128.

28. Dumitrascu T, Chirita D, Ionescu M, Popescu I. Resection for hilar cholangiocarcinoma: analysis of prognostic factors and the impact of systemic inflammation on long-term outcome. J Gastrointest Surg. 2013; 17:913-924. 